\title{
Laboratory standards and guidelines for population- based cystic fibrosis carrier screening
}

Wayne W. Grody, MD, PhD', Garry R. Cutting, MD', Katherine W. Klinger, PhD ${ }^{3}$, Carolyn Sue Richards, $P h D^{4}$, Michael S. Watson, PhD ${ }^{5}$, and Robert J. Desnick, $\mathrm{PhD}, \mathrm{MD}^{6}$ (Subcommittee on Cystic Fibrosis Screening, Accreditation of Genetic Services Committee, ACMG)

In 1997, the National Institutes of Health convened a Consensus Development Conference on Cystic Fibrosis (CF). ${ }^{1}$ The Consensus Conference recommended that genetic screening for CF mutations should be offered to identify carriers among adults with a positive family history of CF, partners of individuals with $\mathrm{CF}$, couples currently planning a pregnancy, and couples seeking prenatal care. A second NIH-sponsored conference that focused on the implementation of the Consensus Conference recommendations was held in 1998. ${ }^{2}$ Shortly thereafter, the American College of Medical Genetics (ACMG) and the American College of Obstetricians and Gynecologists (ACOG), in conjunction with the National Human Genome Research Institute, formed a Steering Committee to coordinate the implementation of population-based CF carrier screening and to develop "Clinical and Laboratory Provider Guidelines" for (1) provider education; (2) laboratory testing, interpretation, and genetic counseling; and (3) patient education and informed consent.

The ACMG charged the Accreditation of Genetic Services Committee, chaired by Dr. Robert Desnick, to establish a Subcommittee on Cystic Fibrosis Carrier Screening (henceforth the "Committee") to develop recommendations and guidelines for optimal laboratory testing, interpretation, and counseling. The Subcommittee, cochaired by Drs. Wayne Grody and Garry Cutting, met twice yearly since October 1998. The issues considered by the Committee included (1) the target population to be screened (universal vs. limited to certain high-risk ethnic groups); (2) the screening model to be used (couple-based vs. sequential); (3) criteria for and selection of the standard mutation testing panel; (4) potential value and use of an extended testing panel with additional mutations; (5) whether to test for mutations and variants associated with mild or nonclassical phenotypes (such as congenital bilateral absence of the vas deferens); (6) test interpretation, reporting, and genetic counseling; and (7) laboratory quality assurance.

The recommendations detailed here have been incorporated into a joint ACMG/ACOG/NIH Steering Committee

\footnotetext{
From the ${ }^{1}$ Divisions of Medical Genetics and Molecular Pathology, UCLA School of Medicine, Los Angeles, California; ${ }^{2}$ McKusick-Nathans Institute of Genetic Medicine, Johns Hopkins University School of Medicine, Baltimore, Maryland; ${ }^{3}$ Genzyme Genetics, Framingham, Massachusetts; ${ }^{4}$ Department of Molecular and Human Genetics, Baylor College of Medicine, Houston, Texas; ${ }^{5}$ American College of Medical Genetics, Bethesda, Maryland; and ${ }^{6}$ Department of Human Genetics, Mount Sinai School of Medicine, New York, New York.

Address for reprints: American College of Medical Genetics, 9650 Rockville Pike, Bethesda, MD 20814-3998.
}

document entitled "Preconceptual and Prenatal Carrier Screening for Cystic Fibrosis" which will be widely distributed. This document also will include guidelines for providers, patient education, and informed consent. Patient education materials will include two pamphlets, entitled "Cystic Fibrosis Carrier Testing. . . The Decision is Yours" and "Cystic Fibrosis Testing: What Happens if Both My Partner and I are Carriers?" It is important to note that these guidelines were prepared for population CF carrier screening and that different testing and counseling strategies would be employed for the identification of the mutation(s) in patients diagnosed with CF or in relatives of CF patients. Such diagnostic and prenatal mutation analyses should be referred to a genetics center for appropriate testing and counseling.

\section{ISSUES TO CONSIDER IN POPULATION CF CARRIER SCREENING}

The cloning of the CF gene, CFTR, in $1989^{3-5}$ provided the ability to screen individuals and couples with no family history of the disease to identify unsuspecting carriers at risk for producing affected children. Analogous to the successful TaySachs disease model for the prevention of recessive diseases, ${ }^{6}$ such screening would identify carrier couples with a one in four risk for affected offspring with each pregnancy and offer them genetic counseling and various reproductive options, including prenatal diagnosis. After much debate and several pilot carrier screening studies, the 1997 NIH Consensus Conference recommended that CFTR mutation testing be made available to all pregnant couples and those contemplating pregnancy. However, implementing the delivery of mass population screening for CF carriers raised many issues and concerns including the following: the large number $(>800)$ of CFTR mutations; the differing prevalence of individual CFTR mutations among various ethnic, demographic, and racial groups; the extreme ethnic heterogeneity of the U.S. population and its increasing admixture; the wide clinical variability of the disorder; the inconsistency of genotype-phenotype correlations for particular mutations; the fact that not all CFTR mutations cause cystic fibrosis; the changing prognosis of the disease in the face of new and novel therapies; the documented lack of interest by nonpregnant couples in being screened and the consequent limitation of options available to at-risk couples who undergo testing during pregnancy; the absence of guidelines for developing an appropriate mutation test panel; and 
the huge anticipated burden that widespread screening would place on existing genetic counseling resources.

Although the Committee recognized the complex issues and problems associated with CF carrier screening in the general U.S. population, it also appreciated that these concerns were of similar magnitude to those in other screening programs already in practice, such as maternal serum multiple marker screening for aneuploidy in the fetus. While there will be foreseen and unforeseen difficulties, the issues and recommendations of the ACMG Subcommittee on CF Carrier Screening represent an attempt to ensure that population-based carrier screening for CFTR mutations will be effective and appropriate.

\section{Target population for carrier screening}

There has been much discussion and debate over which ethnic and racial groups should be offered CF carrier testing in a population-based screening program. Some maintain that screening should be limited to those populations, such as nonJewish Caucasians of European Ancestry and Ashkenazi Jews, in which both the carrier frequency ( 1 in 25 to 30 ) and the detectability of the majority of prevalent mutations (25 mutations detect $>80 \%$ of CF alleles) are sufficiently high to justify efficient and cost-effective screening. Others feel that the marked and growing ethnic admixture in the United States makes it difficult to readily classify or exclude patients based on ethnic group, and that even attempting to make such determinations in a busy clinical setting would place an undue burden on the primary care physician and impair the overall effectiveness and cost of the screening program. While some of the most successful genetic screening programs, such as that for Tay-Sachs disease, have narrowly targeted particular ethnic groups, there is precedent in the newborn screening field for universal screening, despite wide differences in disease incidence among ethnic and racial groups (e.g., newborn screening for sickle cell disease).

\section{Recommendations}

1. The Committee recommends that $\mathrm{CF}$ carrier screening be offered to non-Jewish Caucasians and Ashkenazi Jews, and made available to other ethnic and racial groups who will be informed of their detectability through educational brochures, the informed consent process, and/or other efficient methods. For example, Asian-Americans and Native-Americans without significant Caucasian admixture should be informed of the rarity of the disease and the very low yield of the test in their respective populations. Testing should be made available to African-Americans, recognizing that only about $50 \%$ of at-risk couples will be detected. An educational brochure and a consent form which recites this information as well as a sign-off for those choosing not to be tested after reading these materials is being prepared by the Working Group on Patient Education and Informed Consent.

2. We recommend that preconception testing be encouraged whenever possible, although we recognize that for practical purposes, testing will often occur in the prenatal setting.

\section{Population screening model: Couple versus sequential}

Couple-based screening involves collection and testing of specimens from both partners, with each informed of the results after both have been tested. In the sequential screening model, one member of the couple (usually the woman) is tested first, and if a positive result is obtained, then the partner is tested, with full disclosure of the test results to both individuals. An alternative couple-based model has been proposed ${ }^{7}$ in which specimens are collected from both individuals, but only one partner is initially tested. If that test is positive, then the other partner is tested. Positive/negative couples are reported as if they were negative/negative or negative/not-tested couples in the other two methods.

\section{Recommendation}

Testing should be done using either a couple-based or sequential model, depending on the target population, the nature of the clinical setting, and the appropriate judgment of the practitioner. Couple-based testing is recommended for Caucasian couples of Northern European and Ashkenazi Jewish descent, particularly when concurrently testing for other common genetic disorders in the latter population. The sequential model may be more useful for groups in which the carrier frequency is lower and in situations where obtaining a simultaneous sample from the partner is impractical. In general, the individual provider or center should choose whichever method they feel most appropriate or practical.

While the Committee appreciates some of the psychosocial and cost-saving advantages of the couple-testing model of Wald, ${ }^{7}$ we do not endorse this approach because of ethical questions surrounding nondisclosure of test results and because it deprives the positive member of the positive-negative couple the opportunity of informing his or her relatives of their risk so that they too can be tested, the so-called "cascade effect," an ancillary benefit of primary population screening. ${ }^{8}$

\section{Selection of the mutation panel}

To date, over 900 mutations in the CFTR gene have been identified (http://www.genet.sickkids.on.ca/cftr). The frequency of these mutations has been determined in North American CF patients and in European CF patients, as well as in patients from various ethnic and demographic groups. ${ }^{9-14}$ Other studies have reported the frequency of CFTR mutations from carrier screening in pan-ethnic North American populations, ${ }^{15-17}$ as well as in specific ethnic, demographic, or racial groups. ${ }^{918-20}$ Thus, a standard panel of mutations is required that provides the greatest pan-ethnic detectability and can be practically performed.

\section{Recommendations}

The Committee recommends use of a pan-ethnic mutation panel that includes all CF-causing mutations with an allele frequency of $\geq 0.1 \%$ in the general U.S. population. Allele frequencies should be derived from published sources where phenotype has been confirmed and data have been derived 
from each region of the United States. Publications and Internet databases from collaborative groups such as the CF Genetic Analysis Consortium and independent registries such as that maintained by the U.S. Cystic Fibrosis Foundation serve as excellent sources of information. The Committee recommends that all mutations of this frequency should be included, regardless of whether they have been associated with mild or severe disease. The panel should include mutation subsets shown to be sufficiently predominant in certain ethnic groups, such as Ashkenazi Jews and African Americans, that also have a frequency of $\geq 0.1 \%$ in the general population.

Based on these criteria, the Committee has compiled a standard screening panel of 25 mutations (Table 1), which represents the standard panel that we recommend for screening in the U.S. population. Since our understanding of the distribution and frequency of mutations in CFTR is continually advancing, it is anticipated that the composition of the recommended panel will be reviewed at least annually and revised appropriately. To this end, on-going review of CF allele frequencies in the U.S. population, especially among populations where test sensitivity is low (e.g., Hispanics) is recommended.

\section{Extended mutation panel}

The question has been raised whether an extended or second-tier mutation test panel should be offered to couples testing positive/negative with the standard panel.

\section{Recommendations}

After careful consideration, the Committee recommends that an extended panel should not be offered routinely to such couples, since it would have the effect of increasing patients' anxiety, would appear to endorse an alternative mutation panel beyond the standard panel defined here as the "standard of care" and would provide very low additional yield, leaving such couples who test positive/negative with essentially the same level of uncertainty as they had before. Moreover, it is likely for the foreseeable future that such extended panels may only be available at one or a very few laboratories. It was agreed, however, that the existence of such a panel be made known to couples who request further information and be used on a case-by-case basis as indicated by the clinical situation. Laboratories offering such panels should clearly state in both their advertising and reporting materials the limited increase in carrier detectability which they provide, basing the additional percentage figures on data from the CF Consortium and CF Foundation Patient Registry Annual Data Reports and/or the proposed CDC CF Database rather than their own data.

\section{Testing for congenital bilateral absence of the vas deferens (CBAVD)}

The CFTR mutation $\mathrm{R} 117 \mathrm{H}$, along with the $7 \mathrm{~T}$ variant of the $5 \mathrm{~T} / 7 \mathrm{~T} / 9 \mathrm{~T}$ polymorphism in intron 8 on the same allele (in cis), has been found in a large proportion of otherwise healthy men with infertility due to CBAVD. ${ }^{21-24}$ Also, the 5 T variant paired (in trans) with a CF mutation has been found in men with CBAVD. ${ }^{25}$ Testing for the R117H mutation and the intron 8 variant in a large population screening program will inevitably produce complicated counseling problems, because it will expand the risk ascertainment beyond that for classical CF. While this might be avoided by simply choosing not to screen for the intron 8 variant, that choice would be problematic in itself, since the relatively common $\mathrm{R} 117 \mathrm{H}$ mutation can also cause classical CF when in cis with 5T. ${ }^{23}$

\section{Recommendations}

The Committee recommends that the $\mathrm{R} 117 \mathrm{H}$ mutation be included in the test panel, while recognizing that this will screen for male infertility as well as CF. Thus, to distinguish the genotypes of $\mathrm{R} 117 \mathrm{H}$ associated with $\mathrm{CF}$ from that associated with CBAVD, reflex testing for the $5 \mathrm{~T} / 7 \mathrm{~T} / 9 \mathrm{~T}$ variant is recommended only when the $\mathrm{R} 117 \mathrm{H}$ mutation is positive. If positive for $5 \mathrm{~T}$, the laboratory will request appropriate specimens from family members to determine if the $5 \mathrm{~T}$ polymorphism is in cis or trans with the $\mathrm{R} 117 \mathrm{H}$ allele in order to provide additional

Table 1

Recommended core mutation panel for general population CF carrier screening

\begin{tabular}{|c|c|c|c|c|c|}
\hline \multicolumn{6}{|c|}{ Standard mutation panel } \\
\hline$\Delta \mathrm{F} 508$ & $\Delta \mathrm{I} 507$ & G542X & G551D & W1282X & N1303K \\
\hline R553X & $621+1 \mathrm{G} \rightarrow \mathrm{T}$ & $\mathrm{R} 117 \mathrm{H}$ & $1717-1 \mathrm{G} \rightarrow \mathrm{A}$ & $\mathrm{A} 455 \mathrm{E}$ & $\mathrm{R} 560 \mathrm{~T}$ \\
\hline 2184delA & 1078delT & $3849+10 \mathrm{kbC} \rightarrow \mathrm{T}$ & $2789+5 \mathrm{G} \rightarrow \mathrm{A}$ & 3659delC & $\mathrm{I} 148 \mathrm{~T}$ \\
\hline \multicolumn{6}{|c|}{$3120+1 \mathrm{G} \rightarrow \mathrm{A}$} \\
\hline \multicolumn{6}{|c|}{$\mathrm{I} 506 \mathrm{~V},{ }^{a} \mathrm{I} 507 \mathrm{~V},{ }^{a} \mathrm{~F} 508 \mathrm{C}^{a}$} \\
\hline $5 \mathrm{~T} / 7 \mathrm{~T} / 9 \mathrm{~T}^{b}$ & & & & & \\
\hline
\end{tabular}


information for genetic counseling. In this way, the initial screening will focus on CF and not create unnecessary anxiety concerning the fertility of the fetus, since about $5 \%$ of the U.S. population would be found to have the $5 \mathrm{~T}$ polymorphism if it is included in the primary test panel.

Information about the mutations associated with CBAVD should be included in reports and consent forms. Model laboratory report interpretations are included in the Appendix. Because of the subtle and complicated genetic issues raised, the Committee recommends that the detection of one of these unusual mutation combinations should be followed by referral of the screenee to a geneticist or other expert professional for further counseling and appropriate testing.

\section{Unexpected homozygosity for $\Delta F 507$ or $\Delta F 508$ in healthy individuals due to codon 506, 507, and 508 variants}

Certain test methodologies may not distinguish certain CFTR variants, including I506V, I507V, and F508C, and instead produce a false-positive result for $\Delta \mathrm{I} 507$ or $\Delta \mathrm{F} 508$. I507V and I508V have not been associated with CF; however, F508C has been reported to be associated with CBAVD. Although the frequency of these variant alleles is rare, occasionally an otherwise healthy CF carrier, who also has the rare variant, may be erroneously diagnosed as an affected homozygote. In addition, false results may occur because of polymorphisms at polymerase chain reaction primer hybridization $\operatorname{sites}^{26}$ or other anomalies.

\section{Recommendations}

The Committee recommends that laboratories recognize that non-CF-causing variants at codons 506, 507, and 508 can cause a false-positive result when certain test methodologies are employed. If the screenee is a carrier for $\Delta \mathrm{I} 507$ or $\Delta \mathrm{F} 508$ and also has the I506V, I507V, or F508C variant on the other chromosome, this situation may lead to a false-positive test for homozygosity for the $\Delta \mathrm{I} 507$ or $\Delta \mathrm{F} 508$ mutation. Therefore, each laboratory must validate its testing method for such potential false positives, and should perform reflex testing as appropriate for these variants in healthy individuals who test as $\Delta \mathrm{I} 507$ or $\Delta \mathrm{F} 508$ homozygotes. The I506V and I507V mutations do not produce a phenotype, while F508C has been associated with CBAVD. ${ }^{24}$ Thus, a male who carries $\Delta \mathrm{F} 508$ or $\Delta \mathrm{I} 507$ paired with F508C should be counseled regarding the association of this genotype with male infertility. Laboratories should be aware of similar situations for other CF mutations in the screening panel.

\section{Test reporting and interpretation}

Since a patient with a negative result still has a residual risk for CF heterozygosity depending on her/his ethnic or racial background, the provider will be responsible for informing the screenee and couple of their residual risk. Such calculations are estimates based on the patient's and partner's ethnic and racial background. This information can be provided for each screenee in the test report. In addition, certain mutations are associated with infertility and may require additional testing for appropriate interpretation and genetic counseling.

\section{Recommendations}

Reports should include all information described in the ACMG Standards and Guidelines for Clinical Genetics Laboratories (http://gopher.faseb.org/genetics/acmg/index.html). CF reports should include the reported ethnicity of the patient and the indication for testing (i.e., carrier test, no family history, etc.) as well as the mutations tested and method of testing. Examples of interpretive reports for various testing results are given in the Appendix.

As is well known, both patients and many primary care professionals are not comfortable dealing with relative risks and nonabsolute laboratory test results. It is essential that test reports for negative screens define as accurately as possible, based on current knowledge, the residual risk that the person tested could be a carrier of an untested or unknown mutation. This risk will vary greatly by ethnic group and should be so specified in the test report.

The best current estimates of residual risks for the major ethnic groups after testing negative with the standard mutation panel, listed in the Appendix, will be updated with experience. For those centers doing sequential testing, a positive test report on the first partner should include the recommendation that the other partner be tested.

\section{Quality assurance}

CFTR mutation analysis is a high-complexity laboratory procedure requiring sophisticated molecular biology and human genetics expertise. The advent of population carrier screening for CFTR mutations portends adding an extremely large test volume to a procedure of such high complexity and sophistication, a situation unprecedented in the field of laboratory medicine. For these reasons, it is crucial that such testing be performed by laboratories possessing the requisite expertise, experience, and physical resources.

\section{Recommendations}

Any laboratory embarking on CF population carrier screening must be able to comply with the stringent quality assurance guidelines specified in the ACMG and CAP checklists and the report of the NIH-DOE Task Force on Genetic Testing (www.nhgri.nih.gov/Policy_and_public_affairs/Communications/ Meeting_reports/task-force.html) and must participate in the CAP/ ACMG quality assurance and proficiency testing programs. Equal attention must be paid to pre- and postanalytic aspects of testing (e.g., appropriateness of test ordering, interpretation, reporting, and counseling) as to the laboratory test panel itself.

The Committee recognizes that, in the absence of available commercial test kits, testing for the mutation panel recommended here may be difficult for some laboratories accustomed to smaller panels. It is hoped that our recommendations will lead to some consolidation of testing in the most capable centers as well as some impetus for manufacturers to develop kits and reagents with the standard panel in mind in order to enhance use by additional competent laboratories.

\section{Referral to a genetics center for testing and counseling}

Various test results will generate the need for genetic counseling. Such results will include (1) the identification of posi- 
tive/negative couples who may request additional mutation analyses or counseling to clarify their residual risk, (2) individuals who have a family history of CF, (3) otherwise healthy males who carry mutations or variants associated with infertility, and (4) positive/ positive couples. It is important that individuals and couples receive accurate information about risks, prognostic factors, and range of options available to allow for fully informed decisionmaking. Such services should be available by referral from obstetricians and other primary care physicians who may not feel competent to perform such counseling themselves.

\section{Recommendation}

The Committee recommends that a concise summary of the knowledge and expertise needed relative to $\mathrm{CF}$, human genetics, and the interpretation of CF test results should be provided by the professional who will counsel these patients. Any primary care provider who does not feel comfortable explaining these concepts to the patients should refer them to a genetics professional. We expect that most of the essential material can be adapted from that produced by the Patient Education and Informed Consent Committee.

\section{Approved by the American College of Medical Genetics Board of} Directors on July 8, 2000.

(C) AMERICAN COLLEGE OF MEDICAL GENETICS, 2001

9650 Rockville Pike, Bethesda, MD 20814-3998

Phone 301-530-7127, Fax 301-571-1895

\section{Acknowledgments}

The ACMG Subcommittee on Cystic Fibrosis Screening wishes to thank its ex officio members, Drs. George Cunningham, R. Rodney Howell, Michael Mennuti, and Reed Pyeritz, as well as the ACMG Board of Directors, for their valuable input during the development of this statement.

\section{References}

1. NIH Consensus Development Conference Statement. Genetic testing for cystic fibrosis. April 14-16, 1997. Arch Intern Med 1999;159:1529-1539.

2. Mennuti MT, Thomson E, Press N. Screening for cystic fibrosis carrier state. Obstet Gynecol 1999;93:456-461.

3. Rommens JM, Iannuzzi MC, Kerem B-S, Drumm ML, Melmer G, Dean M, Rozmahel R, Cole JL, Kennedy D, Hidaka N. Identification of the cystic fibrosis gene: chromosome walking and jumping. Science 1989;245:1059-1065.

4. Riordan JR, Rommens JM, Kerem B-S, Alon N, Rozmahel R, Grzelczak Z, Zielenski J, Lok S, Plavsic N, Chou JL. Identification of the cystic fibrosis gene: cloning and characterization of complementary DNA. Science 1989;245:1066-1073.

5. Kerem B-S, Rommens JM, Buchanan JA, Markiewicz D, Cox TK, Chakravarti A Buchwald M, Tsui LC. Identification of the cystic fibrosis gene: genetic analysis. Science 1989;245:1073-1080.

6. Kaback M, Lim-Steele J, Dabholkar D, Brown D, Levy M, Zeiger D. Tay-Sachs disease-carrier screening, prenatal diagnosis, and the molecular era: an international perspective, 1970 to 1993. The International TSD Data Collection Network. JAMA 1993;270:2307-2315.

7. Wald NJ. Couple screening for cystic fibrosis. Lancet 1991;338:1318-1319.

8. Super M, Schwarz MJ, Malone G, Roberts T, Haworth A, Dermody G. Active cascade testing for carriers of cystic fibrosis gene. BMJ 1994;308:1462-1468.

9. Macek M, Mackova A, Hamosh A, Hilman BC, Selden RF, Lucotte G, Friedman KJ, Knowles MR, Rosenstein BJ, Cutting GR. Identification of common cystic fibrosis mutations in African-Americans with cystic fibrosis increases the detection rate to 75\%. Am J Hum Genet 1997;60:1122-1127.

10. Abeliovich D, Lavon IP, Lerer I, Cohen T, Springer C, Avital A, Cutting CR. Screening for five mutations detects $97 \%$ of cystic fibrosis (CF) chromosomes and predicts a carrier frequency of 1:29 in the Jewish Ashkenazi population. Am J Hum Genet 1992;51:951-956.

11. Cystic Fibrosis Genetic Analysis Consortium. Population variation of common cystic fibrosis mutations. Hum Mutat 1994;4:167-177.

12. Estivill X, Bancells C, Ramos C. Geographic distribution and regional origin of 272 cystic fibrosis mutations in European populations. The Biomed CF Mutation Analysis Consortium. Hum Mutat 1997;10:135-154.

13. Cystic Fibrosis Foundation. Cystic Fibrosis Foundation Patient Registry Annual Data Report, 1998. Bethesda, MD: Cystic Fibrosis Foundation.

14. Guilloud-Batailler M, De Crozes D, Rault G, Degioanni A, Feingold J. Cystic fibrosis mutations: report from the French Registry. Hum Hered 2000;50:142-145.

15. Gregg R, Wilfond BS, Farrell PM, Laxova A, Gassemer D, Mischier EG. Application of DNA analysis in a population-screening program for neonatal diagnosis of cystic fibrosis (CF): comparison of screening protocols. Am J Hum Genet 1993;52:616-626.

16. Witt DR, Hallam P, Wi S, Blumberg B, Fishbach A, Holtzman J, Kornfeld S, Lee R, Nemzer L, Palmer R. Cystic fibrosis heterozygote screening in 5,161 pregnant women. Am J Hum Genet 1996;58:823-835.

17. Grody WW, Dunkel-Schetter C, Tatsugawa ZH, Fox MA, Fang CY, Cantor RM, Novak JM, Bass HN, Crandall BF. PCR-based screening for cystic fibrosis carrier mutations in an ethnically diverse pregnant population. Am J Hum Genet 1997;60:935-947.

18. DeMarchi JM, Caskey CT, Richards CS. Screening for diseases frequent in the Ashkenazi Jewish population. Hum Mutat 1996;8:116-125.

19. Eng CM, Schechter C, Robinowitz J, Fulop G, Burgert T, Levy B, Zinberg R, Desnick RJ. Prenatal genetic carrier testing using triple disease screening. JAMA 1997;278:1268-1272.

20. Mercier B, Raguenes O, Estivill X, Morral N, Kaplan GC, McClure M, Grebe TA, Kessler D, Pignatti PF, Merigo C. Complete detection of mutations in cystic fibrosis of Native American origin. Hum Genet 1994;94:629-632.

21. Gervais R, Dumur V, Rigot M-M, Lafitte J-J, Roussel P, Claustres M, Demaille J. High frequency of the $\mathrm{R} 117 \mathrm{H}$ cystic fibrosis mutation in patients with congenital absence of the vas deferens. N Engl J Med 1993;328:446-447.

22. Anguiano A, Oates RD, Amos JA, Dean M, Gerrard B, Stewart C, Maher TA, White MTS, Milunsky A. Congenital bilateral absence of the vas deferens: a primarily genital form of cystic fibrosis. JAMA 1992;267:1794-1797.

23. Kiesewetter S, Macek M, Davis C, Curristin SM, Chu C-S, Graham C, Shrimpton AE, Cashman SM, Tsui C, Mickle J, Amos J, Highsmith WE, Shuber A, Witt DR, Crystal RG, Cutting GR. A mutation in CFTR produces different phenotypes depending on chromosomal background. Nat Genet 1993;5:274-277.

24. Dörk T, Dworniczak B, Aulehis-Schotz C, Wieczorek D, Bhm I, Mayerova A, Seydewitz H, Nieschlag E, Meschede D, Horst J. Distinct spectrum of CFTR gene mutations in congenital absence of vas deferens. Hum Genet 1997;100:367-377.

25. Chillon M, Casals T, Mercier B, Bassas L, Lissens W, Silber S, Romey MC, RuizRomera J, Verlingue C, Claustres M. Mutations in the cystic fibrosis gene in patients with congenital absence of the vas deferens. N Engl J Med 1995;332:1475-1480.

26. Fujimura FK, Northrup H, Beaudet AL, O'Brien WE. Genotyping errors with the polymerase chain reaction. N Engl J Med 1990;322:61.

\section{Appendix \\ Model laboratory reports}

Reported ethnicity: European Caucasian

Indication: Screening/carrier test/negative family history

Methods: The CFTR gene was tested for the presence of these specific mutations (and benign variants when indicated) by polymerase chain reaction (PCR) and allele specific oligonucleotide hybridization. This test was developed and its performance characteristics determined by this laboratory. It has not been cleared or approved by the FDA. The FDA has determined that such clearance or approval is not necessary. This test is used for clinical purposes. It should not be regarded as investigational or for research. The laboratory is regulated under CLIA of 1988.

General disclaimer: DNA studies do not constitute a definitive carrier test for $\mathrm{CF}$ in all individuals. Thus, interpretation is given as a probability. It should be realized that there are many possible sources of diagnostic error.

Genotyping errors can result from trace contamination of PCR reactions and from rare genetic variants that interfere with analysis. Accurate risk calculation requires accurate family history information. Inaccurate reporting of family history of CF will lead to errors in residual risk assessment.

\section{Example of a negative CF report}

Result: Negative for the mutations analyzed. 
Interpretation: It is our understanding that this individual has a negative personal and family history for cystic fibrosis (CF). Using the methodology described, this individual is negative for the $25 \mathrm{CF}$ mutation screening test recommended by the American College of Medical Genetics. These results do not rule out the possibility that this individual could be a carrier of a mutation not detected by this test. The following table provides data to be used in the genetic counseling for this individual. Limited information is available for individuals from other ethnic populations.

\begin{tabular}{|c|c|c|c|}
\hline \multirow[b]{2}{*}{ Ethnic group } & \multirow[b]{2}{*}{$\begin{array}{l}\text { Detection } \\
\text { rate }\end{array}$} & \multicolumn{2}{|c|}{ Estimated carrier risk } \\
\hline & & $\begin{array}{c}\text { Before } \\
\text { test }\end{array}$ & $\begin{array}{c}\text { After negative } \\
\text { test }\end{array}$ \\
\hline Ashkenazi Jewish & $97 \%$ & $1 / 29$ & $\sim 1$ in 930 \\
\hline European Caucasian & $80 \%$ & $1 / 29$ & $\sim 1$ in 140 \\
\hline African American & $69 \%$ & $1 / 65$ & $\sim 1$ in 207 \\
\hline Hispanic American ${ }^{a}$ & $57 \%$ & $1 / 46$ & $\sim 1$ in 105 \\
\hline Asian American & $b$ & $1 / 90$ & $b$ \\
\hline
\end{tabular}

${ }^{a}$ This is a pooled set of data and requires additional information to accurately predict risk for specific Hispanic populations.

${ }^{b}$ No data available.

Note: Residual carrier risk after a negative test is modified by the presence of a positive family history of $\mathrm{CF}$ (i.e., having a first, second, or third degree relative affected with $\mathrm{CF}$ ) and/or by admixture of various ethnic groups. For these specific situations, accurate risk assessment requires standard Bayesian analysis and genetic counseling.

\section{Example of a positive CF report}

Result: $\Delta$ F508 heterozygote.

Interpretation: One copy of the $\Delta$ F508 mutation was identified, indicating that this individual is a carrier for cystic fibrosis (CF). This interpretation is based on the assumption that this individual is not clinically affected with CF. It is recommended that carrier testing by mutation analysis be offered to relatives and reproductive partners of known CF carriers along with appropriate genetic counseling.

\section{Special considerations}

$\mathrm{R} 117 \mathrm{H}$ positive, $5 \mathrm{~T}$ positive, cis/trans undetermined report

Result: R117H heterozygote, 5T positive.

Interpretation: This individual has one copy of the $\mathrm{R} 117 \mathrm{H}$ mutation and one copy of the $5 \mathrm{~T}$ variant. The $\mathrm{R} 117 \mathrm{H}$ mutation has been reported to produce different clinical phenotypes, depending on the chromosomal background that affects splice sites and splicing efficiency (Kiesewetter et al., Nature Genetics 5:274, 1993). The phenotypic expression of the R117H mutation is influenced by the presence of the $5 \mathrm{~T}$ variant. The $\mathrm{R} 117 \mathrm{H}$ mutation produces a partially functional CFTR protein product. The amount produced in the presence of $\mathrm{R} 117 \mathrm{H}$ is further reduced when the $\mathrm{R} 117 \mathrm{H}$ mutation is on the same allele as the $5 \mathrm{~T}$ variant. The laboratory is presently unable to determine whether the $5 \mathrm{~T}$ variant in this patient is on the same or opposite chromosome as the R117H mutation. Thus, we recommend that parents of this individual submit blood samples for mutation analysis to resolve this issue. If parents are unavailable, other close family members may be helpful. Genetic counseling is also recommended.
$\mathrm{R} 117 \mathrm{H}$ positive, $5 \mathrm{~T}$ positive, cis report addendum

Result: $\mathrm{R} 117 \mathrm{H}$ heterozygote, $5 \mathrm{~T}$ positive.

Interpretation: See R117H, 5T positive, cis/trans undetermined report.

Addendum: Follow-up testing of the parents of this individual demonstrated that the $\mathrm{R} 117 \mathrm{H}$ mutation and 5T are located on the same chromosome such that they are in "cis" position. These results indicate that this individual is a carrier of a CF mutation that has been associated with a variable phenotype when this or another CFTR mutation is present in CF patients. Genetic counseling is recommended.

\section{$\mathrm{R} 117 \mathrm{H}$ positive, $5 \mathrm{~T}$ positive, trans report addendum}

Result: $\mathrm{R} 117 \mathrm{H}$ heterozygote, $5 \mathrm{~T}$ positive.

Interpretation: See $\mathrm{R} 117 \mathrm{H}, 5 \mathrm{~T}$ positive, cis/trans undetermined report.

Addendum: Follow-up testing of the parents of this individual demonstrated that $\mathrm{R} 117 \mathrm{H}$ and $5 \mathrm{~T}$ are located on different chromosomes such that they are in "trans" position. These results indicate that this individual is a carrier of a relatively benign or extremely mild CF mutation that is not generally associated with the phenotype of typical CF patients. The presence of $\mathrm{R} 117 \mathrm{H}$ in "trans" with the $5 \mathrm{~T}$ variant has been associated with congenital bilateral absence of the vas deferens (CBAVD), leading to infertility in males and no known clinical features in females.

This individual is also a carrier of the 5T variant. The 5T variant can reduce the amount of functional protein produced from normal or mild mutant CF genes by altering splicing. The 5T variant on one chromosome, in combination with a CF mutation on the opposite chromosome, may lead to male infertility due to CBAVD, with or without mild or atypical symptoms of cystic fibrosis. There is no known clinical signifiance of $5 \mathrm{~T}$ in females. Approximately $63 \%$ of males with CBAVD who are heterozygous for a CF mutation also have the $5 \mathrm{~T}$ variant, while approximately $5 \%$ of the general population who are asymptomatic for CF or CBAVD are heterozygous for the $5 \mathrm{~T}$ allele. The penetrance of $5 \mathrm{~T}$ is reduced and is estimated at about $60 \%$. Therefore, it is difficult to predict the clinical significance of the $5 \mathrm{~T}$ variant. Genetic counseling is recommended.

\section{$\mathrm{R} 117 \mathrm{H}$ positive, $5 \mathrm{~T}$ negative report}

Result: R117H heterozygote, 5T negative.

Interpretation: This individual has one copy of the R117H mutation. The R117H mutation has been reported to produce different clinical phenotypes depending on the chromosomal background that affects splice sites and splicing efficiency (Kiesewetter et al., Nature Genetics 5:274, 1993). The phenotypic expression of the $\mathrm{R} 117 \mathrm{H}$ mutation is influenced by the presence of the $5 \mathrm{~T}$ variant. Thus, additional testing was performed, and the results indicated that this individual is negative for the $5 \mathrm{~T}$ variant. In the absence of the $5 \mathrm{~T}$ variant, the $\mathrm{R} 117 \mathrm{H}$ mutation is not expected to lead to a typical CF clinical phenotype. The presence of $\mathrm{R} 117 \mathrm{H}$, however, has been associated with CBAVD, leading to infertility in males with no known clinical features in females. Population screening has shown a 19-fold higher than predicted number of carriers of the R117H mutation. Genetic counseling is recommended.

These standards and guidelines are designed primarily as an educational resource for medical geneticists and other health care providers to help them provide quality medical genetic services. Adherence to these standards and guidelines does not necessarily ensure a successful medical outcome. These standards and guidelines should not be considered inclusive of all proper procedures and tests or exclusive of other procedures and tests that are reasonably directed to obtaining the same results. In determining the propriety of any specific procedure or test, the geneticist should apply his or her own professional judgment to the specific clinical circumstances presented by the individual patient or specimen. It may be prudent, however, to document in the patient's record the rationale for any significant deviation from these standards and guidelines. 